\title{
GÊNERO, DOMINAÇÃO MASCULINA E FEMINISMO: Por uma Teoria Feminista do Direito
}

\section{Thiago Burckhart}

Mestrando em Direito no Programa de Pós-Graduação em Direito da Universidade Federal de Santa Catarina (UFSC). Graduado em Direito pela Universidade Regional de Blumenau (Furb). Pesquisador bolsista Capes do Grupo de Estudos em Constitucionalismo Político (UFSC). Pesquisador do Centro Didattico Euroamericano Sulle Politiche Costituzionali (Università Del Salento, Itália). Pesquisador do Núcleo de Estudos em Constitucionalismo, Internacionalização e Cooperação (Constinter/Furb). thiago--rafa@hotmail.com

Recebido em: 21/1/2017

Aceito em: 22/3/2017

\section{Resumo}

Tomando em consideração as incursões que ocorreram entre Direito e feminismo nas últimas décadas e séculos e a projeção normativa dos direitos das mulheres, este artigo tem por finalidade analisar o feminismo enquanto movimento político-cultural e sua relação com 0 Direito contemporâneo. Procura-se fornecer subsídios teóricos para a construção de uma teoria crítica e feminista do Direito, preocupada com a superação de visões e práticas do patriarcado no plano institucional que subjulgam uma enorme gama de sujeitos. A partir disso, pode-se afirmar que o Direito passou por profundas evoluções aquisitivas nas últimas décadas no que diz respeito à conquista de direitos que contestam o patriarcado, mas há a necessidade de repensar e subverter a lógica de práticas patriarcalistas remanescentes no campo das instituições jurídicas. Para tanto, optou-se pela abordagem sociológica e antropológica, a partir de autores como Pierre Bourdieu e Judith Butler e da teoria crítica do Direito. 0 artigo divide-se em três seções: 1 - Dominação masculina, poder simbólico e patriarcado; 2 - Gênero e desconstrução: a contribuição de Judith Butler; 3 - Direito e feminismo.

\section{Palavras-chave}

Feminismo. Direito. Teoria crítica. Gênero. Dominação masculina.

\section{Gender, masculine domination and feminism: the feminist legal theory}

\section{Abstract}

Taking in consideration the recent dialogues that occurred between law and feminism in past decades and centuries, and its normative projection in rights of women, this article aims to analyze feminism as a political and cultural movement and its relation with contemporary 
law. It provides theoretical subside to the construction of a feminist and critical theory of law, concerned with the overcoming of patriarchal institutional practices that subjugate many subjects. It is conclusive that law has undergone by profound acquisitive evolutions in the last decades in terms of recognizing rights that contest patriarchy. But, there is a necessity to rethink and subvert the logic of patriarchal practices remaining in the field of juridical institutions. Hence, this article has been made thought a sociological and anthropological approach, from authors as Pierre Bourdieu and Judith Butler. This article is divided in three parts: 1 - Pierre Bourdieu: masculine domination, symbolic power and patriarchate; 2 - Judith Butler: gender and deconstruction; 3 - Law and feminism.

\section{Keywords}

Feminism. Law. Critical theory. Gender. Masculine domination.

\section{Sumário}

1 Introdução. 2 Dominação masculina, poder simbólico e patriarcado. 3 Gênero e desconstrução: a contribuição de Judith Butler. 4 Direito e feminismo. 5 Considerações Finais. 6 Referências. 


\section{INTRODUÇÃO}

O patriarcado marca a construção das sociedades ocidentais há milênios, desde a Antiguidade clássica, e pode ser entendido como um sistema político-cultural de opressão que se difunde por meio da dominação simbólica dos detentores do padrão de poder generificado (homens) sobre mulheres e demais seres subjugados. Esse paradigma construiu ao longo da História uma série de representaçôes sociais, culturais e políticas que passaram a ser internalizadas e externalizadas no âmbito das instituiçôes políticas e sociais, entre eles o Direito.

No século 18, entretanto, esse paradigma - mais que naturalizado - passou a ser paulatinamente questionado por meio de revoltas sociais, que tiveram como protagonistas as mulheres na reivindicação de direitos políticos. Ao longo do século 20 outras demandas políticas e culturais fizeram com que o paradigma dominante e hegemônico do patriarcado fosse sendo gradualmente contestado, sobretudo a partir dos chamados novos movimentos sociais que fizeram uma releitura dos tradicionais movimentos sociais e tiveram como protagonistas não somente as feministas, mas também o movimento Lésbicas, Gays, Bissexuais e Transgêneros (LGBT), o movimento negro, indígena, entre outros.

Nesse sentido, as incursóes no plano político e cultural fizeram com que o Direito passasse a assumir uma dimensão emancipatória, prevendo uma série de dispositivos normativos (bem como decisóes judiciais) que buscam a igualdade de gênero. Pode-se afirmar que um dos instrumentos de dominação ideológica do patriarcado, o Direito, passa cada vez mais a ser renovado tendo em vista as reivindicaçóes sociais e as epistemologias feministas. No plano institucional, contudo, observa-se que ainda remanescem discursos e práticas que invocam concepçóes sexistas. Trata-se de uma das grandes contradições para o Direito contemporâneo.

Nesse sentido, este artigo tem por objetivo analisar, desde uma abordagem sociológica e antropológica, bem como a partir da teoria crítica do Direito, a relação existente entre o Direito, o patriarcado e o feminismo, com base na perspectiva de gênero e sexualidade, de modo a conceber as recentes transformaçóes jurídicas que caminham no sentido inverso ao patriarcado/machismo e a necessidade de constru- 
ção de uma teoria feminista do Direito. Busca responder às seguintes perguntas: É possível se falar de uma teoria feminista do Direito atualmente? Qual feminismo se advoga? Quais suas implicaçôes em termos práticos e institucionais?

Para tanto, o texto divide-se em três partes: 1 - Dominação masculina, poder simbólico e patriarcado; 2 - Gênero e desconstrução: a contribuição de Judith Butler; 3 - Direito e feminismo.

\section{DOMINAÇÃO MASCULINA, PODER SIMBÓLICO E PATRIARCADO}

Pierre Bourdieu, sociólogo francês, é um dos grandes pensadores e teóricos do século 20, que se preocupou em refletir - entre outros temas - sobre a temática do poder. Nesse sentido, Bourdieu buscou analisar as relaçóes informais de poder, naquilo que chamou de poder simbólico (BOURDIEU, 1989), diga-se, as relaçóes de poder que não eram costumeiramente estudadas no âmbito acadêmico-científico.

$\mathrm{Na}$ visão de Bourdieu o poder simbólico faz parte de uma "estrutura estruturada" da sociedade ocidental, de modo que está incorporado no âmbito das relações socioculturais implicitamente e subjetivamente. É uma forma de poder que contribui sobremaneira para a manutenção do status quo, operando sutilmente a partir do controle ideológico de massas, possível a partir da comunicação e do discurso - que se transformam em performatividades. ${ }^{1}$

Nesse sentido, a objetividade do mundo passa a ser interpretada e calcada em uma subjetividade estruturante, ${ }^{2}$ de modo que o poder simbólico é a estrutura que dá sentido à existência e à compreensão da vida e das estruturas sociais. ${ }^{3}$ Os símbolos são entendidos como elementos que, no sentido antropológico, produzem

1 Para aprofundamentos, ver BARTHES, 2001. Para entender o conceito de performatividade, ver TIBURI, 2014.

2 "Na tradição idealista, a objetividade do sentido do mundo define-se pela concordância das subjectividades estruturantes (senso = consenso)." (BOURDIEU, 1989, p. 8).

3 "O poder simbólico é um poder de construção da realidade que tende a estabelecer uma ordem gnoseológica: sentido imediato do mundo (e, em particular, do mundo social) supóe aquilo a que Durkheim chama o conformismo lógico, quer dizer, 'uma concepção homogênea do tempo, do espaço, do número, da causa, que torna possível a concordância entre as inteligências”' (BOURDIEU, 1989, p. 9). 
sentidos e significados no campo social, de modo que criam "integraçáo social", tornando possível o "consenso acerca do sentido do mundo social que contribui fundamentalmente para a reprodução da ordem social: a integração 'lógica' é a condição de integração moral" (BOURDIEU, 1989, p. 10).

A reprodução é a condição pela qual o simbólico se difunde, produzindo seus efeitos em grande escala (e criando aquilo que Bourdieu denomina de habitus). Sua reprodução ocorre no plano do discurso, que é entendido como uma relação de poder. A dominação simbólica, ao ter por objetivo a perpetuação de uma dominação de uma classe sobre outra, assegura essa dominação por meio daquilo que Bourdieu chama de "violência simbólica". Essa violência é calcada na ideia de capital simbólico que por meio de açóes e discursos perpetua as relaçóes de dominação.

Desse modo, “o poder simbólico é, com efeito, esse poder invisível o qual só pode ser conhecido com a cumplicidade daqueles que não querem saber que lhe estão sujeitos ou mesmo que o exercem" (BOURDIEU, 1989, p. 7-8). A corrupçáo do modo de compreender o mundo que o poder simbólico exerce faz com que as classes sociais desfavorecidas passem a aceitar sua condição de dominadas, isto é, a naturalizar e neutralizar sua situação de subordinação, tornando-se cúmplices de sua própria dominação.

Os sistemas simbólicos produzem capital, ou seja, valor que se autovaloriza, e se exerce em diversos planos da vida como capital social, capital cultural, capital econômico, entre outros. Assim, Bourdieu compreende que o Direito enquanto instituição social também exerce um poder simbólico perante a sociedade. Isso ocorre porque a autoridade jurídica possui o poder de "nomeação", no qual está em jogo o monopólio do poder de impor o princípio universalmente reconhecido de conhecimento do mundo social ${ }^{4}$ e da interpretação legítima.

\footnotetext{
4 Assim, "o direito é, sem dúvida, a forma por excelência doo poder simbólico de nomeação que cria as coisas nomeadas e, em particular, os grupos; ele confere a estas realidades surgidas das suas operaçóes de classificação toda a permanência, a das coisas, que uma instituição histórica é capaz de conferir a instituiçôes históricas. O direito é a forma por excelência do discurso actuante, capaz, por sua própria força, de produzir efeitos. Não é demais dizer que ele faz o mundo social, mas com a condição de se não esquecer que ele é feito por este" (BOURDIEU, 1989, p. 237).
} 
A autoridade jurídica representaria, na visão de Bourdieu, "a forma por excelência da palavra autorizada, palavra pública, oficial, enunciada em nome de todos e perante todos" (1989, p. 236), criando enunciados performativos. Em razão disso, o Direito - enquanto meio de dominaçáo social - seria um importante instrumento das classes dominantes para a produção de um mundo em que seus privilégios estivessem assegurados. ${ }^{5}$

Isso ocorre porque em sua visão o Estado possui o direito de monopólio da violência simbólica, e é por meio deste que ela se reproduz. O poder simbólico seria, portanto, legitimado pelo Estado e pelas demais formas de poder que imperam, como o capital (mercado). A partir disso, o poder simbólico passa a se desenvolver nos mais variados "campos" da vida, gerando representaçôes, discursos e práticas sociais.

Nesse sentido, uma das recorrentes formas de poder e violência simbólica é a dominação masculina. Trata-se do exemplo por excelência da submissão paradoxal da violência simbólica - violência suave, insensível, invisível - a suas próprias vítimas, que se exerce essencialmente pelas vias puramente simbólicas da comunicação e do conhecimento, ou está no princípio não só da realidade como também da representação da realidade (BOURDIEU, 2002, p. 1-2).

A dominação perpassa uma série de representações e mitologias ${ }^{6}$ que constroem socialmente os corpos no contexto social. Os discursos, ${ }^{7}$ por sua vez, moldam a estruturação dessa dominação de modo a situar e conformar os gêneros e as sexualidades de acordo com a determinação cultural, estabelecendo hierarquia entre eles e fazendo com que o macho se sobreponha à fêmea. Essa visão patriarcal e androcêntrica faz, portanto, com que se crie um conjunto de oposição entre os sexos, de modo a estabelecer uma divisão do mundo entre o feminino e o masculino.

\footnotetext{
5 "A constituição do campo jurídico é um princípio de constituição da realidade (isto é, verdadeiro em relação a todo o campo). Entrar no jogo, conformar-se com o direito para resolver o conflito, é aceitar tacitamente a adoção de um modo de expressão e de discussão que implica a renúncia à violência física e às formas elementares da violência simbólica, como a injúria” (BOURDIEU, 1989, p. 229). Deve-se ter em vista, entretanto, que o direito também pode assumir uma conotaçáo emancipatória, tal como observa Boaventura de Sousa Santos (1999).

6 Para uma compreensão da relação entre sexualidade e mitologia, ver: HIGHWATER, 1992.

7 Para uma análise da relação entre a sexualidade e os discursos de poder, ver FOUCAULT, 1988, 1984.
} 
Esses esquemas de pensamento, de aplicação universal, registram como que diferenças de natureza, inscritas na objetividade das variações e dos traços distintivos (por exemplo em matéria corporal) que eles contribuem para fazer existir, ao mesmo tempo que as "naturalizam", inscrevendo-as em um sistema de diferenças, todas igualmente naturais em aparência (BOURDIEU, 2002, p. 8). ${ }^{8}$

Nesse sentido, ao reproduzir-se no plano dos discursos e do habitus, a dominação masculina, calcada na visão androcêntrica, dispensa justificação, pois é vista como neutra e natural. Assim, "o mundo social constrói o corpo como realidade sexuada e como depositário de princípios de visão e de divisão sexualizantes" (BOURDIEU, 2002, p. 23). ${ }^{9}$ Trata-se de todo um sistema de dominação que não exerce única e somente uma imposição sobre a mulher - apesar de que no caso das mulheres a imposição é mais nítida e aviltante - mas também sobre os próprios homens, de todos aqueles que não se ajustam corporalmente ao padrão europeu (branco, proprietário e cristão/judeu), e sobre as representaçóes que são feitas de sua atuação no meio social, como a imposição de virilidade. ${ }^{10}$

Nesse contexto, as masculinidades foram construídas a partir do medo dos homens pelo feminino, isto é, de serem identificados com as representaçóes oriundas do mundo feminino, tendo em vista que essa identificação faz com que sua posição social de "macho" seja posta em xeque, sendo este "inferiorizado". A distinção cultural dos corpos, portanto, está inscrita nas coisas e

(...) se inscreve também nos corpos através de injunçóes tácitas, implícitas nas rotinas da divisão do trabalho ou dos rituais coletivos ou privados (basta lembrarmos, por exemplo, as condutas de marginalização impostas às mulheres

8 Nesse mesmo sentido, "a divisão entre os sexos parece estar 'na ordem das coisas', como se diz por vezes para falar do que é normal, natural, a ponto de ser inevitável: ela está presente, ao mesmo tempo, em estado objetivado nas coisas (na casa, por exemplo, cujas partes são todas 'sexuadas'), em todo o mundo social e, em estado incorporado, nos corpos e nos habitus dos agentes, funcionando como sistemas de esquemas de percepção, de pensamento e de açáo" (BOURDIEU, 2002, p. 9).

9 Nesse sentido, "a definição social dos órgãos sexuais, longe de ser um simples registro de propriedades naturais, diretamente expostas à percepção, é produto de uma construção efetuada à custa de uma série de escolhas orientadas, ou melhor, através da acentuaçáo de certas diferenças, ou do obscurecimento de certas semelhanças" (BOURDIEU, 2002, p. 15).

10 "O privilégio masculino é também uma cilada e encontra sua contrapartida na tensão e contensão permanente, levadas por vezes ao absurdo, que impóe a todo homem o dever de afirmar, em toda e qualquer circunstância, sua virilidade” (BOURDIEU, 2002, p. 56). 
com sua exclusão dos lugares masculinos). As regularidades da ordem física e da ordem social impóem e inculcam as medidas que excluem as mulheres das tarefas mais nobres (BOURDIEU, 2002, p. 26).

Desse modo, ao naturalizar a racionalidade patriarcal nas coisas, as mulheres também passaram a reproduzir o esquema de dominação, que as levaram a uma representação negativa de seu próprio sexo, de modo a perpetuar os discursos e as práticas machistas. Toda essa racionalidade, portanto, converteu-se em um senso comum autoritário e conservador, numa razão indolente que deve ser superada (cfe. SANTOS, 2002) a partir de uma crítica política e social, mas que não se restrinja somente a ela, tendo em vista que é um poder institucionalizado social e politicamente.

Só uma ação política que leve realmente em conta todos os efeitos de dominação que se exercem através da cumplicidade objetiva entre as estruturas incorporadas (tanto entre as mulheres quanto entre os homens) e as estruturas de grandes instituições em que se realizam e se produzem não só a ordem masculina, mas também toda a ordem social (a começar pelo Estado, estruturado em torno da oposição entre sua "mão direita”, masculina, e sua "mão esquerda", feminina, e a Escola, responsável pela reprodução efetiva de todos os princípios de visão e de divisão fundamentais, e organizada também em torno de oposiçóes homólogas) poderá, a longo prazo, sem dúvida, e trabalhando com as contradiçóes inerentes aos diferentes mecanismos ou instituiçóes referidas, contribuir para o desaparecimento progressivo da dominação masculina (BOURDIEU, 2002, p. 129).

Nesse sentido, Bourdieu afirma que a Sociologia pode ser utilizada como uma arma de denúncia desta realidade naturalizada e não percebida pela maior parte das pessoas. De fato, apesar de ser uma estrutura que se desenvolve pela reprodução, cabe ressaltar que o patriarcado vem sendo paulatinamente questionado, seja por meio dos movimentos políticos, seja por meio da sociedade civil organizada. ${ }^{11}$ A emancipação desse padrão de organização social, portanto, não pode ser visto como uma linearidade perpétua, podendo ser rompido, denunciado e destruído.

${ }^{11}$ Judith Butler afirma que "The notion of a universal patriarchy has been widely criticized in recente years for its failure to account fo the working of gender oppression in the concrete cultural contexts in which it exists" (BUTLER, 1990, p. 3). 


\section{GÊNERO E DESCONSTRUÇÃO: A CONTRIBUIÇÃO DE JUDITH BUTLER}

Judith Butler, filósofa estadunidense, é uma das grandes teóricas sobre gênero e sexualidade da contemporaneidade. Butler constrói uma teoria sobre o gênero pautada no desconstrutivismo e no pós-estruturalismo. Aproximando-se da teoria de Bourdieu, Butler afirma que "power appeared to operate in the production of that very binary frame for thinking about gender” (BUTLER, 1990, p. VIII), de modo que as relaçôes de gênero são também relações de poder que geram dominação tanto intersubjetiva quanto intrasubjetiva.

São as relaçôes de poder, entretanto, que constituem a identidade. A identidade, como argumenta Stuart Hall, constitui-se a partir da diferença, e portanto, é dependente desta, posto que é o pilar estruturante de sua própria estruturação (HALL, 2012). Como parte da dimensão simbólica das relaçôes sociais, as identidades mostram-se como uma faceta "importante" da vida, tendo em vista que é a partir dela que se define e se projeta o seu próprio sentido. No que tange, porém, às questôes de gênero e sexualidade, Butler afirma que existe uma compulsory order, gerada a partir das relaçóes político-sociais que delimitam espaços e açóes dentro da separação entre o masculino e o feminino, pressupondo uma radical identificação do corpo sexualizado com o gênero.

Dessa forma, the body appears as a passive medium on which cultural meanings are inscribed or as the instrument through which an appropriative and interpretative will determines a cultural meaning for itself. O gênero - assim como a sexualidade - é produto de uma histórica relação de dominação cultural que objetifica os corpos conforme os interesses de domínio e poderio prevalecentes. Em razão disso, Butler empreende uma radical crítica às noçôes de gênero e identidade, de modo a propor a desconstrução de suas características e de seus padróes preestabelecidos.

Nesse contexto, Butler desconstrói a ideia de mulher e consequentemente o sujeito histórico do feminismo. Butler elabora uma teoria do feminismo calcada nos corpos abjetos. Nesse sentido, o feminismo é a luta pelos direitos das mulheres, mas também é a desmontagem do que se convencionou chamar de mulher e de homens. O questionamento central da teoria de Judith Butler se dá com relação à noção de identidade, seu princípio e sua lógica. Isso porque o feminismo pensado na lógica da binaridade de gênero reproduz aquilo mesmo que quer criticar. 
Judith Butler procura desconstruir o processo de significação:

The subject is not determined by the rules through which it is generated because signification is not a founding act, but rather a regulated process or repetition that both conceals itself and enforced its rules precisely through the production of substantializing effects (BUTLER, 1990, p. 145).

A teoria de Butler mostra-se bastante provocativa, tendo em vista que a modernidade foi construída com fulcro em binaridades - bem e mal, belo e feio, inclusão e exclusão, branco e preto, entre outras. A desconstrução dessas dicotomias, que se mostra mais que necessária, estremece as próprias bases que sustentaram os discursos da modernidade. Aí está a dimensão de sua provocação. Nesse sentido, Butler realiza uma crítica à razáo dual da modernidade, conjugando a necessidade de superar dicotomias que foram construídas ao longo dessa época e da imposição do patriarcado.

O corpo sexuado é uma das bases que dá sustentação ao patriarcado, pois é a partir dessa característica biológica que se construíram os sentidos e os discursos de dominação. Sobre esse corpo sexualizado recai a noção de "generificação", que se desenvolve a partir da repetição:

Gender is the repeated stylization of the body, a set of repeated acts within a highly rigid regulatory frame that congeal over time to produce the appearance of substance of a natural sort of being. A political genealogy of gender ontologies, if it is successful, will deconstruct the substantive appearance of gender into its constitutive acts and locate and account for those acts within the compulsory frames set by the various forces that police the social appearance of gender (BUTLER, 1990, p. 33).

A repetição de práticas e discursos que petrificam os gêneros estão intrinsecamente relacionados à noçáo de identidade como um ideal normativo, que se assenta numa inteligibilidade cultural binária. ${ }^{12}$ Nesse sentido, as identidades são

12 “(...) persons only become intelligible through becoming gendered in conformity with recognizable standards of gender intelligibility” (BUTLER, 1990, p. 16). 
impostas aos corpos de acordo com o sexo que se possui, de modo que qualquer desvio desse padrão é marginalizado. Isso dá sustentação a conceber esse fenômeno como uma opressão de gênero.

As identidades são, portanto, construídas por meio de discursos e práticas que buscam concretizar a noção de essência de um indivíduo. Da mesma forma, entretanto, que o discurso e as práticas operam no sentido de construir o gênero, Butler também afirma que esses mecanismos produzem a sexualidade e o desejo. ${ }^{13}$ Ou seja, os padrōes de gênero e a concepção binária entre as duas categorizações produzem uma inevitável imposiçáa sobre o desejo e o comportamento sexual das pessoas, que se assenta na lógica da heterossexualidade. Butler afirma que a sociedade vive em uma "heterosexual matrix", ou seja, "the production of a given regime of sexuality that seeks to regulate sexual experience by instating the discrete categories of sex as foundational and causal functions within any discursive account" (1990, p. 23).

Butler entende, assim, que a sexualidade é construída e regulada a partir dos mecanismos de poder imperantes em uma sociedade, que reproduzem a lógica do patriarcado e do falocentrismo:

If sexuality is culturally constructed within existing power relations, then the postulation of a normative sexuality that is "before", "outside" or "beyond" power is a cultural impossibility and a politically task of rethinking subversive possibilities for sexuality and identity within the terms of power itself" (1990, p. 31).

Dessa forma, as relaçôes socioculturais criam uma gama de representaçôes simbólicas que dão sustentação tanto às diferenças de gênero quanto às imposições no terreno da sexualidade, que imprimem uma "ordem" que é entendida como "normal", ao passo que os que se desviam dessa noçáo de normalidade (homos-

13 "Both masculine and feminine positions are thus instituted through prohibitive laws that produce culturally intelligible gendders, bt only through the production of an unconscious that reemerges in the domain of the imaginary" (BUTLER, 1990, p. 28). Nesse sentido, sobre a imaginação, ver SARTRE, 2008. 
sexualidade, bissexualidade, intersexualidade, assexualidade, transgêneros, entre outros) são relegados ao estado de loucura, e em razão disso patologizados, dentro de um regime de regulação dos sexos e das sexualidades.

A crítica de Butler avança no mesmo caminho daquele percorrido por Michel Foucault. O pensador francês desenvolveu uma crítica à opressão que se desenvolve por meio dos discursos no âmbito da sexualidade. $\mathrm{O}$ controle da sexualidade e do prazer não ocorreu somente por meio das instituiçóes tradicionais, como a Igreja Católica, mas também por meio da ciência e do discurso científico. ${ }^{14}$ Esses discursos, que eram - e em certos contextos ainda são - encarados como verdades, passaram a exercer um domínio no plano da subjetividade e das práticas dos sujeitos, de modo a controlá-los. A esse controle de corpos docilizados pelo discurso Foucault atribui a categoria biopolítica ou biopoder. Trata-se de um poder intrinsecamente relacionado ao dispositivo que introjeta uma falsa ideia de libertação.

E lá, onde hoje vemos a história de uma censura dificilmente suprimida, reconhecer-se-á, ao contrário, a lenta ascensão, através dos séculos, de um dispositivo completo para nos fazer falar do sexo, para lhe dedicarmos nossa atenção e preocupação, para nos fazer acreditar na soberania de sua lei quando, de fato, somos atingidos pelo mecanismos de poder da sexualidade (BUTLER, 1990, p. 148).

Esse cenário permite conceber a necessidade de superar certas convenções socialmente firmadas com o intuito de garantir maior liberdade e autonomia ao sujeito e, consequentemente, à sociedade. A teoria de Butler segue nesse sentido, na constatação de uma série de imposiçôes sociais, assumidas de modo praticamente irrefletido e acrítico, e que acabam por perpetuar a reprodução de uma violência simbólica.

14 "O exame médico, a investigação psiquiátrica, o relógio pedagógico e os controles familiares podem, muito bem, ter como objetivo global e aparente dizer náo a todas as sexualidades errantes ou improdutivas mas, na realidade, funcionam como mecanismos de dupla incitação: prazer e poder" (FOUCAULT, 1988, p. 52). Com relação em específico à homossexualidade, observa-se a ocorrência de sua psiquiatrização, enquanto "prazer perverso". 
A desconstrução da categoria de gênero e, consequentemente, dos sujeitos históricos que a produziram, implica superar a lógica binária que funda o pensamento ocidental no plano social. Também implica a superação de uma cultura autoritária e conservadora que, se reproduz por meio de discursos e não pelo diálogo, ${ }^{15}$ por meio da homogeneização e não pelo respeito à singularidade de cada ser humano.

Nesse sentido Judith Butler fornece subsídios para a crítica do próprio feminismo moderno e de sua dimensão político-cultural, uma crítica em grande proporçáo que, de certo modo, reinvente o feminismo. $\mathrm{O}$ entrecruzamento entre Direito e feminismo, portanto, não pode perder de vista esta crítica estrutural de Butler, sobretudo no sentido de pensar e construir práticas emancipatórias no terreno institucional, da chamada prática jurídica.

\section{DIREITO E FEMINISMO}

De fato o Direito moderno constituiu-se sob as sólidas bases do patriarcado. A Declaração Universal dos Direitos do Homem e do Cidadão, promulgada na França em 1789, revelando-se um marco tanto para os direitos humanos como para o constitucionalismo, é uma clara evidência da influência do patriarcado na racionalidade jurídica, a começar pela nomenclatura utilizada: homem e cidadão. Nem mesmo no plano da linguagem jurídica as mulheres e todos aqueles que não se identificam com o binarismo homem versus mulher tiveram espaço.

Em razão disso, foi declarada naquela mesma época a Declaração Universal dos Direitos da Mulher e da Cidadã (1791), escrita pela francesa Olympe de Gouges. Este foi o primeiro documento a prever a igualdade jurídica entre as mulheres e homens. Promulgou também os direitos das mulheres à segurança, ao voto, o acesso às instituiçóes públicas, liberdade profissional, além dos direitos de propriedade. A

\footnotetext{
${ }^{15}$ Nesse sentido, "a ética, enquanto ético-política, precisará questionar todo discurso, enquanto o discurso é a fala pronta e dominadora que manipula o outro, que o apaga ao manipulá-lo, em nome do diálogo que é a fala que se faz com o abismamento no outro" (TIBURI, 2014, p. 17).
} 
Declaração, entretanto, foi rejeitada pela Assembleia Nacional, na qual ingressou para votação e promulgação formal. Além disso, a Declaração foi completamente ignorada tanto em termos políticos quanto acadêmicos. ${ }^{16}$

Observa-se, portanto, que o Direito moderno tomou para si o discurso da universalidade. A universalidade e a abstratividade de direitos na era moderna serviram de legitimação de inúmeras injustiças, tanto políticas quanto institucionais. A dita universalidade, contudo, assumia o padrão preestabelecido dos donos do poder, quais sejam, homens, brancos, proprietários, cristáos e heterossexuais. Aqueles que não se identificavam com este padrão foram relegados à marginalidade na garantia de direitos, de modo que a universalidade revelou-se falaciosa. ${ }^{17}$

Nesse sentido, pode-se questionar, assim como fizeram outros autores (RABENHORST, 2011), se o Direito possui sexo e gênero? A resposta a essa pergunta dependerá do ponto de um ponto de vista, contudo, numa perspectiva histórica, pode-se afirmar que sim. Se o Direito for entendido não somente como um conjunto de normas abstratas, mas também como um conjunto de instituiçóes, práticas, concepçóes, ideologias, culturas e políticas, pode-se concluir que as concepçôes institucionais refletem a ideologia dominante na sociedade. ${ }^{18}$ Ademais, os gender studies, que têm Judith Butler como um de seus ícones, já evidenciou que o Direito foi construído a partir da noção e da perspectiva de gênero. ${ }^{19}$

Ao longo da História, entretanto, pode-se observar que houve uma incursão do movimento feminista com o Direito. O movimento feminista clássico, conhecido como feminismo liberal, produziu frutíferas transformaçóes ao menos no plano

\footnotetext{
${ }^{16}$ A Declaração pode ser acessada no seguinte endereço eletrônico: <http://www.direitoshumanos. usp.br/index.php/Documentos-anteriores-\%C3\%A0-cria\%C3\%A7\%C3\%A3o-da-Sociedade-das-Na\%C3\%A7\%C3\%B5es-at\%C3\%A9-1919/declaracao-dos-direitos-da-mulher-e-da-cidada-1791.html>

${ }^{17}$ Há que se defender, contudo, a universalidade como valor intrínseco aos direitos humanos, sobretudo a partir do recente processo de internacionalização dos direitos humanos ocorrido após 1945, e sua interpretaçâo ser realizada mediante um diálogo intercultural. Para uma análise mais profunda desse processo, ver DULCE, 2014; FLORES, 2007.

${ }^{18}$ Ideologia é aqui entendida na sua acepção marxista. Para aprofundamentos, ver CHAUÍ, 1980.

19 "No centro ontológico das instituiçốes modernas está um sujeito em torno do qual foi constituída e ordenada a realidade: o sujeito masculino. $\mathrm{O}$ direito posto não deixou de incorporar esse fato" (SOUSA, 2015, p. 17).
} 
normativo. Diversos direitos foram conquistados, como o direito ao voto, ao trabalho, à cidadania, à propriedade, à liberdade, entre outros. Uma série de direitos de liberdade foram alcançados, além da enunciação formal de igualdade entre homens e mulheres, como ocorre na Constituição brasileira de 1988 , em seu artigo $5^{\circ}$.

O feminismo enquanto movimento de reivindicação política, cultural e jurídica, moldou-se às novas interfaces e novas questóes sociais que foram surgindo ao longo dos anos. Atualmente pode-se falar na emergência de um feminismo radical, concernido com uma profunda transformação cultural da sociedade. Esses novos feminismos ${ }^{20}$ lutam ainda hoje tanto pela reivindicação de direitos quanto pela efetivação e concretização dos direitos já conquistados. Nesse sentido,

En las sociedades de supremacía masculina, el punto de vista masculino domina la sociedad civil bajo la forma de un estándar objetivo; ese punto de vista que, por ser dominante en el mundo, no parece funcionar en absoluto como mero punto de vista. Bajo este escudo, el hombre domina a mujeres e nińos; tres cuartas partes del mundo. Las reglas de la familia y del parentesco, y las costumbres sexuales, garantizan la propiedad reproductiva y el control y acceso sexual para los hombres como grupo. Las jerarquías entre los hombres se ordenan sobre la base de la raza y la clase, estratificando también a las mujeres. El Estado incorpora estos hechos del poder social, en y como derecho. Dos cosas ocurren: el derecho deviene legítimo y la dominación social se hace invisible. El legalismo liberal es, em consecuencia, un medio para hacer a la dominación masculina tanto invisible como legítima, a través de la adopción del punto de vista masculino en el derecho, al mismo tiempo que refuerza dicha visión em la sociedad (MACKINNON, 1993, p. 155). ${ }^{21}$

A intersecção do movimento feminista com o Direito, entretanto, representou uma grandiosa vitória para a conquista de direitos civis e políticos às mulheres e a todos aqueles que não se identificam com o padrão masculino, patriarcal, de dominaçáo masculina, anteriormente vigente no plano jurídico. O maior desafio,

${ }^{20}$ Entendo que o feminismo deve ser entendido em sua pluralidade, por isso fala-se de feminismos no plural.

${ }^{21}$ Ressalta-se que a concepçáo de Direito abordada pela autora transcende à noção de Direito apenas como norma. 
contudo, para os tempos modernos é 1) reconhecer novos direitos, aprimorando o plano normativo e, o mais importante, 2) concretizar os direitos já adquiridos, mediante a construção de uma nova cultura jurídica, que leve em consideração seus efeitos institucionais e práticos no plano da vida.

Nesse sentido, nasce a questão central deste artigo: Será possível construir uma teoria feminista do Direito? E se for, qual seria seu objetivo e de que forma surtiria efeitos na prática jurídica? Qual feminismo, entre uma gama de concepçôes, se invocaria? A resposta a essas questôes demanda um esforço hermenêutico no sentido da emancipação não somente dos sujeitos do feminismo, mas de todas as racionalidades e práticas sociais de diferença negadas pelo poder institucional e político do patriarcado. ${ }^{22} \mathrm{O}$ feminismo, pensado dessa maneira, seria positivo tanto para as mulheres quanto para os homens.

Parte-se do pressuposto de que "a teoria do direito, enquanto forma de saber, deveria, assim, ter a capacidade de ser reflexiva na dupla dimensão em que alude esta palavra: reflexão, pensamento, mas também reflexo, como uma imagem projetada num espelho" (RABENHORST, 2011, p. 8). A reflexão que se propóe, portanto, busca rever os paradigmas em que o Direito se encontra inserido, sobretudo no que tange à cultura jurídica, isto é, ao conjunto de práticas, concepçóes, ideologias, símbolos e significados que compóem o mundo jurídico. No plano estritamente normativo, contudo, pode-se observar que há uma série de garantias instrumentais e institucionais que preveem a igualdade e liberdade, conquistadas pelo movimento feminista. O que interessa, portanto, é fazer com que esses instrumentos e as instituiçốes assumam um papel em prol do feminismo e das garantias de liberdade e plena igualdade, isto é, passem a levar o feminismo a sério.

O desafio que se impóe nessa reflexão é conceber a efetividade do Direito sob um novo paradigma, um paradigma feminista. Isto implica a revisão de padrôes jurídicos estabelecidos ao longo da modernidade. Nesse sentido, a teoria crítica do

${ }^{22}$ Nesse sentido, ver SANTOS e MENESES, 2010. A noção de epistemologias do sul, aqui, representam aquelas racionalidades que foram historicamente negadas pela racionalidade central europeia, entendida pelos autores como epistemologias do norte. Para uma análise a partir da complexidade desse fenômeno no plano jurídico, em específico no constitucionalismo latino-americano, ver BURCKHART, 2016. 
Direito, movimento que nasce a partir de uma crítica endógena do mundo jurídico, não pode ver-se como uma teoria alheia ao próprio feminismo, de modo que se precisa dele para funcionar de forma igual e libertária.

Nesse contexto, a abordagem feminista tem muito a contribuir para o Direito. Isso se dá em razão da

[...] compreensão renovada da relação igualdade/diferença; questionamento da separação público/privado com a conseqüente reivindicação de interferência da justiça na esfera doméstica; defesa da idéia de que os particulares também podem violar direitos humanos; propositura de outras formas de soluçáo de conflitos, e assim por diante (RABENHORST, 2011, p. 16).

A intersecção do pensamento feminista com a teoria do Direito, criando uma teoria feminista do Direito, precisa reivindicar uma nova abordagem do e para o Direito. Uma abordagem que leve em consideração os excluídos em razão de sua condição de gênero e sexual, trabalhando tanto normativamente quanto praticamente no plano da igualdade, combatendo o machismo e a dominaçáo patriarcal, que operam institucional e politicamente. Isso implica levar o feminismo a sério como prática intelectual, cultural e jurídica.

O feminismo, como já mencionado, só pode ser plenamente entendido no seu plural, como feminismos. Em razão disso, uma visão contemporânea do feminismo deve levar em consideração a complexidade da teoria política, no sentido de que o feminismo radical não pode negar o feminismo clássico, tendo em vista que esse último resultou em significativos resultados positivos naquele tempo e que surtem efeitos até os dias de hoje.

Volta-se à questão central: Será possível construir uma teoria feminista do Direito? Se isso implicar a libertaçáo dos corpos de mulheres e homens subjulgados em razão da lógica normativa e práticas jurídicas imperantes, penso que sim; se isso implicar a redefinição de conceitos, subversão dos padrôes institucionais de prática jurídica, penso que sim. A conclusão é uma proposição, pois caberá a nós, juristas, colocarmos em prática o feminismo na esfera jurídica, buscando a construção de uma sociedade mais livre, igual e solidária. 


\section{CONSIDERAÇÕES FINAIS}

O patriarcado é um sistema ideológico, axiológico e político-institucional que prima pela supremacia masculina, como metáfora de um padrão de comportamento e de uma lógica de convivência. É uma característica do mundo ocidental, que foi construído desde a Idade Antiga. Reproduz-se mediante um poder simbólico, imperceptível aos olhos dos despercebidos, que opera na subjetividade dos sujeitos. Trata-se de um mecanismo de poder, de dominaçáo, mas que passou recentemente a ser paulatinamente contestado.

O feminismo surgiu como antítese ao patriarcado, reivindicando uma série de direitos civis e políticos às mulheres. Ao longo dos séculos, entretanto, o feminismo desenvolveu-se no sentido de lutar por novos direitos e causas. $\mathrm{O}$ feminismo de Judith Butler desmonta o sujeito histórico do movimento, qual seja, as mulheres, em prol de um feminismo dos corpos abjetos. De fato, o machismo é um complexo sistema de opressão que não atinge unicamente as mulheres, mas todos aqueles que não compartilham do padrão do homem europeu (branco, proprietário, cristão e heterossexual).

Daí a necessidade de repensar a teoria feminista e sua prática intelectual e aliá-la ao Direito, que historicamente foi um instrumento "masculino", isto é, que esteve ao lado dos homens padronizados (detentores do poder, ícones do padrão de poder generificado). As incursóes entre o feminismo e o Direito produziram uma série de avanços no plano normativo, que reconheceram um cardápio de direitos não somente de liberdade, mas também sociais, culturais, econômicos, reprodutivos, às mulheres.

O Direito, entretanto, não se restringe às normas e estende-se ao campo da cultura jurídica, instituições, concepções, ideais e práticas que são alheias às normas. Nesse sentido, unir o Direito (tanto teórica quanto praticamente) ao feminismo hodiernamente, implica a subversão de conceitos, ideais e concepçóes, mas, sobretudo, de práticas jurídico-culturais. A crítica deve operar no sentido de desvendar o véu da ideologia que recobre as práticas jurídicas e que vende a ideia de neutralidade do Direito. 
A partir disso, o feminismo poderá servir de um excelente instrumento para rever e repensar a epistemologia e a prática jurídica, seus discursos e instituiçóes. Será possível uma teoria feminista do Direito? A conclusão projeta-se como proposiçáo, pois caberá a nós colocarmos em prática o feminismo, buscando a construçáo de uma sociedade mais livre, igual e solidária

\section{REFERÊNCIAS}

BARTHES, Roland. Mitologias. Tradução Rita Buongermirio. 11. ed. Rio de Janeiro: Bertrand Brasil, 2001.

BOURDIEU, Pierre. O poder simbólico. Tradução Fernando Tomaz. Difusão Editorial: Lisboa, 1989.

. A dominação masculina. 2. ed. Tradução Maria Helena Kühner. Rio de Janeiro: Bertrand Brasil, 2002.

BURCKHART, Thiago. Constitucionalismo na América Latina: a refundação do Estado e as epistemologias do sul. Curitiba: Editora Prismas, 2016.

BUTLER, Judith. Gender trouble: feminism and the subversion of identity. Nova York: Routledge, 1990.

CHAUÍ, Marilena. O que é ideologia. São Paulo: Brasiliense, 1980.

DECLARAÇÃO dos Direitos da Mulher e da Cidadã. 1791. (Documento). Disponível em: <http://www.direitoshumanos.usp.br/index.php/Documentos-anteriores-\%C3\%A0-cria\%C3\%A7\%C3\%A3o-da-Sociedade-das-Na\%C3\%A7\%C3\%B5es-at\%C3\%A9-1919/ declaracao-dos-direitos-da-mulher-e-da-cidada-1791.html>.

DULCE, Maria José Fariñas. Democracia y pluralismo: una mirada hacia la emancipación. Madrid: Dykinson, 2014.

FLORES, Joaquín Herrera. La reinvención de los Derechos Humanos. Sevilla: Atrapasueños, 2007.

FOUCAULT, Michel. História da Sexualidade I - a vontade de saber. Tradução Maria Thereza da Costa Albuquerque e J. A. Guilhon Albuquerque. Rio de Janeiro: Ediçôes Graal, 1988. . Microfisica do poder. Tradução Roberto Machado. Rio de Janeiro: Ediçóes Graal, 1984. 
HALL, Stuart. Quem precisa de identidade? In: SILVA, Tomaz Tadeu (Org.); HALL, Stuart; WOODWARD, Kathryn. Identidade e diferença: a perspectiva dos Estudos Culturais. Petrópolis, RJ: Vozes, 2012.

HIGHWATER, Jamake. Mito e sexualidade. São Paulo : Ed. Saraiva, 1992.

MACKINNON, Catharine. Hacia una teoría feminista del derecho. Tradução Mariella Dentone. Revista Derecho y Humanidades, año II, n. 3/4, 1993.

RABENHORST, Eduardo Ramalho. Encontrando a teoria feminista do direito. Prima Facie, v. 9, p. 7-24, 2011.

SANTOS, Boaventura de Sousa. Pelas mãos de Alice: o social e o político na pós-modernidade. 7. ed. Porto: Ediçôes Afrontamento, 1999.

SANTOS, Boaventura de Sousa. A crítica da razão indolente: contra o desperdício da experiência. 4. ed. São Paulo: Cortez, 2002.

SANTOS, Boaventura de Sousa; MENESES, Maria Paula. (Org.). Epistemologias do Sul. São Paulo: Ed. Cortez, 2010.

SARTRE, Jean-Paul. A imaginação I. Tradução Paulo Neves. Porto Alegre: L\&PM, 2008.

SOUSA, Rita Mota. Introdução às teorias feministas do Direito. Porto: Ediçóes Afrontamento, 2015.

TIBURI, Marcia. Filosofia prática: ética, vida cotidiana e vida virtual. Rio de Janeiro: Record, 2014. 